\title{
Los tipos ideales en la práctica: significados, construcciones, aplicaciones
}

\author{
Fernando SÁnchez de Puerta Trujillo \\ Universidad de Córdoba \\ spuerta@uco.es
}

Recibido: 12.12 .2004

Aceptado: 18.09 .2005

\begin{abstract}
«En nuestro ámbito existen, para emplear una expresión de F.T. Vischer, "buscadores de materiales" y "buscadores de sentido". El inextinguible apetito de hechos de los primeros sólo puede saciarse con documentos, con tablas estadísticas y encuestas, pero son insensibles al refinamiento del nuevo pensamiento. La gula de los segundos echa a perder el gusto por los hechos a través de siempre nuevos destilados conceptuales... la auténtica capacidad artística... suele manifestarse en la sabiduría para crear algo nuevo mediante la relación de hechos conocidos con puntos de vista también conocidos."
\end{abstract}

(Weber, 1982 (1922): 100-101)

\section{INTRODUCCIÓN}

La cita con la que encabezamos este artículo hace referencia a las cualidades de los tipos ideales y evoca el quehacer de muchos economistas y sociólogos de nuestros días. A veces, nos obsesionamos con encontrar algo que introducir en el SPSS u otro software estadístico similar para poder publicar en las revistas que sólo valoran datos, ecuaciones, curvas, etc. En ocasiones nos empeñamos en definir conceptos cuya utilidad es, al menos, dudosa. Pensemos, por ejemplo, en el del centón coevolucionario («coevolutionary patchwork quilt») de Richard Norgaard (1994), que en un español mas descriptivo y exacto se traduciría como «manta hecha de un gran número de piececitas de paño o tela de diversos colores coevolucionaria». Esta noción pretende decirnos por dónde debe transcurrir el devenir histórico de las sociedades agrarias. Cada una de estas sociedades junto con su agroecosistema, con el cual evoluciona a la par, es una de las piececitas que componen la manta multicolor, que a la postre, sería el planeta tierra y su habitantes. El concepto no deja de ser una bonita utopía. Situaciones como la anterior, sin embargo, no son más criticables que aquellas dedicadas a la elaboración de un verdadero «centón», tal como se define este término en el Diccionario de la Real Academia de la Lengua Española en su tercera acepción, es decir, como una «obra literaria en verso o prosa, compuesta enteramente, o en la mayor 
parte, de sentencias y expresiones ajenas». Ya existen numerosos centones en torno a Weber. Nuestra intención es sistematizar las ideas del sociólogo alemán sobre los tipos ideales dispersas en su obra para, a partir de ellas y de nuestras reflexiones, intentar «operativizar» la construcción de aquellos y su aplicación práctica.

El lector estará de acuerdo con nosotros en que la recuperación de los clásicos continúa siendo una tarea necesaria e inacabada.

Existen algunos trabajos en los que se analiza y critica la metodología sociológica weberiana en conjunto. De entre ellos, vamos a citar, por orden cronológico, los de Abrahan Kaplan (1964), Arthur Stinchcombe (1968), Paul Lazarsfeld (1972), Julian Freund (1986), Martín Albrow (1990 y 1991) y Stephen Kalberg (1994). Los tres primeros son de carácter crítico y proponen corregir ciertos aspectos de la metodología que nos ocupa para acercarla a los enfoques de estos autores. Estas críticas incluyen propuestas para cambiar el término con el que referirse al concepto de tipo ideal con el objeto de dejar más clara su esencia. Así, Lazarsfeld propone llamarlo «espacio de atributos» y Kaplan nos invita a denominarlo «concepto límite»: algo que ya hizo el propio Weber (1982: 82). El trabajo de Freund es el más didáctico de todos los que hemos conocido, aunque no profundice demasiado en los tipos ideales y otros aspectos de la sociología comprehensiva weberiana al querer abarcar en un solo texto, no muy extenso, otras cuestiones además de las metodológicas, como el análisis de las distintas ramas de la sociología abordadas por Weber . El libro de Albrow de 1990, quizás el más difundido, es excelente y se centra en cuestiones metodológicas, pero no lo hace con el propósito con el que abordamos nosotros el concepto weberiano de tipo ideal. Por último, el trabajo de Kalberg, ampliamente citado en la actualidad, exhaustivo en el uso de fuentes directas, entra en una de las cuestiones que vamos a desarrollar: la de los tipos ideales como generadores de hipótesis, pero no nos explica como elaborar éstas a partir de aquellos.

Además de los trabajos en los que se aborda la metodología weberiana, de forma general, existen escritos dedicados específicamente a los tipos ideales. Vamos a referirnos aquí a dos artículos que hemos encontrado en la literatura sociológica (aunque existan otros). Nos referimos al de Susan J. Hekman (1983) y el de Tore Lindbekk (1992). Hekman se propone revalorizar los tipos ideales a partir de la consideración de que Weber, con su concepto, realiza una integración actor-estructura al establecer tipos ideales para la acción y para la dominación que se relacionan entre sí uno a uno. También nos plantea la autora norteamericana unas fases en la construcción de tipos ideales, sin dejarnos del todo claro como construir uno, ya que dichas fases le sirven para distinguir la construcción de «tipos ideales históricos y sociológicos». Las fases a que se refiere Hekman son: i) la determinación de la categoría de hechos a partir de los cuales construir un tipo; ii) la elección del(os) periodo(s) histórico(s) y sociedad(es) particular(es) utilizados como base empírica; y iii) la elección de una serie de elementos particulares del grupo de hechos seleccionados para la construcción del concepto (Hekman, 1983: 123-125). La diferencia entre la construcción de tipos ideales 
históricos y sociales se encuentra en la segunda fase en la que, siempre según Hekman, el historiador se basa en un solo periodo histórico y una sociedad particular, mientras que el sociólogo utiliza una variedad de casos para elaborar sus tipos. El trabajo que más nos ha aportado para el objetivo de este artículo es el de Lindbekk. El sociólogo noruego ha realizado una revisión exhaustiva de los trabajos en que Weber desarrolla de forma dispersa y evolutiva, según demuestra, su metodología de tipos ideales. Lindbekk se queja de que Weber «no clarificara su método de forma adecuada» (1992: 286). Su opinión es que dicha situación se debe al hecho de que Weber desarrollara y aplicara el concepto en un debate con los autores de su tiempo. Lindbekk dedica una gran parte de su artículo a analizar las posturas de dichos autores y confrontarlas con las de Weber recurriendo a un gran número de escritos de éste, pero cuando llega al punto en el que quiere aclarar que es un tipo ideal y cuales son sus implicaciones metodológicas se basa esencialmente en fuentes secundarias. En concreto en el trabajo de Burguer (1987), que define el concepto a partir de las palabras del propio Weber, simplificando éstas y aportando ideas propias no muy esclarecedoras (Burguer, 1987: 87 citado en Lindbekk, 1992: 290). Debemos admitir que Weber, como veremos en el apartado segundo de este artículo, definió bastante mejor que Burguer su concepto y las implicaciones de éste, aunque no nos explicara, como ya hemos comentado, la forma de construirlo o utilizarlo. Lo anterior no significa que Lindbekk no acuda también a las fuentes originales. Lo hace para plantear algunas ideas como que un tipo ideal es un modelo y no una hipótesis, aunque puedan elaborase éstas a partir de aquél o la de que los tipos ideales deben construirse a partir de elementos claros y no ambiguos. Una manera de lograr esto último -para Lindbekk- es definir «opuestos conceptuales como 'secta' e 'iglesia' o como 'capitalismo moderno' versus 'economía de la ciudad medieval'» (Lindbekk, 1992: 290).

Nuestro artículo se estructura en tres partes, además de la presente. El apartado segundo se dedica a sistematizar las recomendaciones metodológicas más importantes de Weber sobre la esencia de los tipos ideales, sobre sus diferencias con otras clases de conceptos, sobre el uso - así como los riesgos de una mala utilización - de aquellos, y sobre el significado de la presencia de tipos ideales en una disciplina como la sociología o la historia. Esta parte de nuestro artículo tiene cierto carácter de "centón» en la acepción de este término de escrito exhaustivo de citas literales de otros autores, pero es necesaria para llegar a los apartados siguientes. Además, pensamos que el lector tiene derecho a disfrutar de una de las prosas científicas más ricas de nuestra disciplina, a la que nosotros no podríamos acercarnos ni por asomo. Ello, a pesar de que mi maestro y amigo Alfonso Ortí opine que la muerte repentina del autor no permitiera una revisión estilística final de muchos de los textos. En dicho apartado hacemos uso de algunas de las obras de Max Weber, en las que desarrolló y aplicó su metodología de tipos ideales, y de varios libros de otros autores que han tratado el tema a partir de los escritos del sociólogo alemán. Podemos afirmar que ninguno de ellos lo hace de una forma «operativa» como pretendemos nosotros, aunque lo hagamos 
conscientes de arriesgarnos a caer en la vulgaridad y no conseguir hacer la divulgación conceptual que nos proponemos.

El tercer y cuarto apartados de nuestro escrito sí que son enteramente de propio cuño. El primero de ellos se dedica a explicar de una forma clara cómo se construyen tipologías ideales. Weber nos ha dejado muchos ejemplos de su concepto, pero, tal como señala Julien Freund, a quien debemos la mejor síntesis, en nuestra opinión, de la metodología sociológica weberiana, «... sólo trazó las grandes líneas, sin entrar en todos los detalles de las implicaciones metodológicas (de los tipos ideales, el paréntesis es nuestro)...» (Freund, 1986 y 1975). En nuestra opinión, Weber se dedicó a elaborar compulsivamente tipos ideales intentando cubrir las facetas económica, social, política, jurídica, religiosa y hasta musical de la realidad (Giner, 1978: 554 y ss.). Para ello, se vio obligado a volver una y otra vez a la historia, de forma igualmente apremiante, en busca de los casos empíricos que le servían como base. Es lógico, entonces, que no le quedara tiempo para explicar lo que estaba haciendo, ni tampoco para decirnos que se podía -o el mismo iba a- hacer después con ello. Martin Albrow ha establecido -citando a Tenbruck- que los ensayos metodológicos de Weber «fueron solamente subproductos de su obra y no su esencia. La exploración empírica fue su tarea central y tenía prioridad sobre otras formas de indagacion» (1991: 76). Baste entonces con que nuestro autor escribiera sobre el resultado de sus investigaciones. Como es sabido «Economía y Sociedad», con lo grandioso de la obra, se trata de un proyecto inconcluso. Probablemente, Weber, y lo que sigue puede ser una afirmación aventurada, no se enfrentó nunca a Marx, como han señalado algunos autores, sino que intentó superarlo como deducimos de su proyecto global y de sus comentarios. No es de extrañar que nuestro autor padeciera depresiones nerviosas durante las cuales no podía recibir visitas ni dar clases, probablemente fruto del stress intelectual, aunque también por problemas familiares explicitados en sus biografias. Es probable que se adelantara a su tiempo siendo víctima de lo que ahora se denomina «ansiedad social generalizada». Lo positivo de esas situaciones es que si uno sale de ellas, y Weber lo hizo, y de que gracias a la herencia que recibió le debemos su amplio legado escrito.

En este artículo distinguiremos cuatro procedimientos para la elaboración de tipologías ideales, que no agotan otras posibilidades y que denominamos de forma resumida: abstracción simple, revisión histórica, lógica dialéctica y tendencia social. Estas formas de proceder serán ilustradas con ejemplos tomados de otros autores o de nuestro propio quehacer científico. El cuarto y último apartado lo dedicamos a intentar aclararnos sobre la utilidad real de los tipos ideales. Ahí haremos referencia a tres clases de aplicaciones prácticas, que tampoco tienen la intención de cubrir todas las utilidades posibles y que responden a las ideas que esbozó Weber. Veremos como un tipo ideal o un conjunto de ellos sirven, en primer lugar, para llegar a un lenguaje común a la hora de hablar o escribir sobre un concepto sociológico. En segundo lugar, los tipos ideales nos permiten compararlos con realidades empíricas para obtener conclusiones. Por último, los tipos ideales son útiles para la formulación de hipótesis, tal como 
dejó entrever el propio Weber. Dentro de esta tercera aplicación distinguiremos tres formas de hacer: formular hipótesis a partir de un tipo ideal, en base a la relación entre varios tipos y, por último, sobre el desarrollo de éstos.

\section{EL CONCEPTO DE «IDEALTYPUS» EN LA OBRA DE MAX WEBER}

Max Weber tomó el término «Idealtypus» de su colega alemán el historiador Georg Jellinek y dedicó una parte importante de su esfuerzo intelectual al concepto que desarrolló con ese nombre y aplicó a una gran diversidad de aspectos de la realidad social a lo largo de toda su obra.

En esta parte de nuestro artículo vamos a intentar compilar una serie de ideas sobre el concepto de tipo ideal tal como las planteó Weber. Simplemente, con el ánimo de organizar nuestra exposición, vamos a dividir esas ideas en cuatro apartados: i) Qué es y qué no es un tipo ideal y cuáles son las diferencias entre éste y un «concepto de género»; ii) Hasta qué punto pueden los tipos ideales ayudarnos en la conceptualización de una realidad social y cómo deben hacerlo; iii) Los riesgos de la utilización de tipos ideales; y iv) La oportunidad y el significado de la presencia de tipos ideales en una disciplina. La mayoría de estas ideas se encuentran en la obra Gesammelte Aufsätzê zur Wissenschaftslehre de 1922 ( «Compilación de Ensayos para una Doctrina de la Ciencia», traducida al español como «Ensayos sobre Metodología Sociológica», 1982). Sin embargo, para entender la esencia del concepto y sus implicaciones metodológicas, debemos acudir a otros escritos donde Weber desarrollo sus ideas al tiempo que las aplicaba a cuestiones como: el capitalismo (Protestantische Ethik, 1901); antiguas formas de organización económica agraria (Wirtschaftsgeschichte, 1923); o al cristianismo (Wirtschaft und Gesellschaft. Grundiss der Verstehender Soziologie, 1922); sin considerar la burocracia, la acción social, la dominanción y otros ejemplos más comúnmente citados. También vamos a apoyarnos en otros trabajos como el de Julien Freund (1986): el esfuerzo de sistematización de las ideas de Weber que, en nuestra opinión, aporta más claridad al entendimiento de su metodología respecto a los tipos ideales. Según Lindbekk: «La causa de la extendida falta de comprensión (de los tipos ideales, el paréntesis es nuestro) debería buscarse en la lectura fragmentada que hace la sociología moderna de la obra de Weber más que en una evaluación considerada de la metodología de éste» (1992: 296).

i) En palabras de Weber: «Un tipo ideal... se obtiene... mediante el realce unilateral de uno o de varios puntos de vista y la reunión de una multitud de fenómenos singulares, difusos y discretos, que se presentan en mayor medida en unas partes que en otras o que aparecen de manera esporádica, fenómenos que encajan en aquellos puntos de vista, escogidos unilateralmente, en un cuadro conceptual en sí unitario. Este en su pureza conceptual, es inhallable empíricamente en la realidad: es una utopía que plantea a la labor historiográfica la tarea de comprobar en que medida la realidad se acerca o se aleja de ese cuadro ideal...» 
(1982: 79-80). Podemos comprobar como su definición es precisa y exhaustiva, aunque no muy esclarecedora «para un lego», como diría el propio Weber. Quizás sea más inteligible para alguien que se acerque por primera vez a esta idea otra sentencia expresada más adelante en el mismo escrito que, además, nos da pistas sobre una de las utilidades de un tipo ideal. Para nuestro autor, su propuesta «... tiene el significado de un concepto límite puramente ideal, respecto del cual la realidad es medida y comparada a fin de esclarecer determinados elementos significativos de su contenido empírico» (1982: 82). Desde luego el término «medida» es empleado de forma metafórica, ya que un tipo ideal nunca se formula como una o varias variables cuantitativas. Aunque, si atendemos al ya citado artículo de Lindbekk (1992), en un ensayo de 1913 sobre categorías sociológicas titulado «Uber einige Kategorien der verstehende Soziologie», Weber planteaba que «los tipos ideales deberían ser utilizados como puntos de partida para análisis estadísticos de probabilidades y medias» (Weber, 1913: 444-448 citado por Lindbekk, 1992. 293). Paul Honigsheim, en su libro sobre Weber, señala como éste clasificaba las ciencias según su carácter nomotético o idiográfico: «Las ciencias naturales pertenecen en su mayor parte a las ciencias nomotéticas, que se ocupan de la cristalización de las regularidades, mientras que las ciencias idiográficas se refieren al conocimiento de acontecimientos singulares» (Honigsheim, 1977: 106). Estos acontecimientos singulares a los que se refiere Honigsheim son la base para cualquier forma de proceder a la hora de construir tipos ideales. En otro lugar, Weber ilustra la dificultad de coincidencia entre la realidad y el tipo ideal con un ejemplo tomado de la física. Así, considerara que un tipo ideal es como «una reacción física calculada sobre el supuesto de un espacio absolutamente vacío» (1993b: 17). Martín Albrow ha comentado que los tipos ideales «no son espejos sino plantillas, sensores más que luces» (1991: 80).

Weber dedica algún espacio en los «Ensayos» a explicarnos que el término «ideal» nunca debe entenderse como positivo, deseable, perseguible, ejemplar, sino como abstracto, puro, lógico, utópico. Advierte, más adelante, y en la misma obra, que es posible que un tipo ideal sea percibido normativamente y no rechaza de forma explícita esa situación. En relación con lo primero, nos dice: «... la noción de "debe ser", de "ejemplaridad", debe ser cuidadosamente distinguida de estas formaciones conceptuales, "ideales" en un sentido puramente lógico... Trátase de la construcción de conexiones que parecen como suficientemente motivadas para nuestra fantasía, esto es, como "objetivamente posibles", adecuadas respecto de nuestro saber nomológico" (1982:81). Aunque, tres páginas después, señala: «Un tipo ideal de una determinada situación social, que admite ser abstraído a partir de ciertos fenómenos sociales característicos de una época, puede - y con mucha frecuencia es este el caso- haber estado presente para los propios contemporáneos como ideal por alcanzar prácticamente o como máxima para la regulación de determinadas relaciones sociales». (1982: 84). Nosotros nos hemos atrevido a utilizar los tipos ideales con fines normativos (Sánchez de Puerta, 1994) siguiendo las recomendaciones de Albrow de que «sus usos son tanto cognitivos como normativos» (1991: 86). 
Puede que la comparación con los conceptos de género que realiza Weber nos diga algo más sobre la esencia de un tipo ideal. El sociólogo alemán compara sus tipos ideales con esos conceptos que según expresa «... se limitan a la mera reunión de lo común a los fenómenos empíricos...» (1982: 90). El autor es muy crítico con respecto a esta clase de conceptos. Especialmente con los «conceptos colectivos tomados del lenguaje cotidiano», como el de intereses económicos agrarios que utiliza para ilustrar su crítica. Después de un análisis de los conflictos de intereses individuales que podemos encontrar en la agricultura, simplemente considerando el precio de la tierra, Weber señala una serie de ideas absolutamente vigentes en el debate intelectual agrario actual. Ideas que plasman la complejidad del tema que trata y que un concepto de género por su carácter simplificador obvia. Creemos que es interesante reproducir íntegramente sus palabras: «... cuando hablamos de "intereses de la economía agraria" por regla general no pensamos sólo en aquellos valores materiales e ideales a los cuales los agricultores mismos refieren sus "intereses", sino también en las ideas de valor, en parte totalmente heterogéneas, a las cuales podemos referir la economía agraria. Por ejemplo: intereses relativos a la producción, derivados del interés de una alimentación razonable y - lo que no en todos los casos coincide con ello- cualitativamente mejor de la población; en este respecto, los intereses de la ciudad y del campo pueden contraponerse de las más diversas maneras, y el interés de la generación presente no tiene por qué ser idéntico con el interés probable de las generaciones futuras. Intereses relativos a la población, en particular a una población agraria más numerosa, derivados de intereses "del Estado", de política interna o externa, o de otros intereses ideales de diversos tipos, por ejemplo, relativos a la esperada influencia que una población agraria numerosa tiene sobre la originalidad cultural de un país. Estos intereses relativos a la población pueden contraponerse a los de los sectores de la población agraria» (1982: 97-98).

ii) Max Weber no estaba del todo seguro de la validez de su propuesta que debería ser demostrada a través del éxito en la tarea para la cuál fue diseñada. En este sentido, expresa: «... es imposible decidir a priori si se trata de un puro juego conceptual o de una formación de conceptos científicamente fructífera; también aquí existe un único criterio: el de su éxito para el conocimiento de fenómenos culturales concretos en su conexión, su condicionamiento causal y su significación. » (1982: 81).

En palabras de Freund, «Weber tenía plena conciencia de los defectos de su teoría de la que sólo trazó las grandes líneas, sin entrar en todos los detalles de las implicaciones metodológicas...». Debemos señalar, no obstante, que esas dudas de Weber no impedían que le plantara cara a sus detractores antes de que estos lo criticaran. Según Freund, «... respondió por adelantado a sus eventuales censores invitándolos a meditar en sus proposiciones "mientras que no estén capacitados para sustituirlas por algo mejor") (Freund, 1986: 65, citando a Weber como *Wissenschaftslehre, pág. 196). En efecto, Weber llega a afirmar que: «Si el historiador... rechaza un intento de formular un tipo ideal... sea consciente o 
inconscientemente, aplica otras (construcciones teóricas) semejantes sin formulación expresa ni elaboración lógica, o bien permanece en el ámbito de lo "experimentado" de manera indeterminada» (1982: 83).

Weber no quiso entrar en el análisis del «...caso más importante de construcciones típico ideales: el de Marx» (Weber, 1982: 92), el cuál se propuso estudiar más adelante en su Revista de Historia. Pero, no pudo evitar hacer continuas referencias a los modos de producción marxianos. Estos son tipos ideales de uno de los conceptos sociológicos más amplios: el de sociedad. Weber pensaba que podíamos elaborar tipos ideales de sociedad (1982: 80), incluso de procesos de desarrollo. Ya que, según nuestro autor: «También los procesos de desarrollo admiten, por cierto, ser construidos como tipos ideales, y estas construcciones pueden revestir altísimo valor heurístico» (1982: 90). El ejemplo con el que ilustra esto último nos señala además la posibilidad de una tipología ideal dialéctica: «...se puede caracterizar la "idea" del "artesanado"... Cabe intentar, luego, delinear una sociedad en la que todas las ramas de la actividad económica, y hasta de la espiritual, estén regidas por máximas que se nos aparecen como aplicación del mismo principio, característico del "artesanado"... Es posible, como paso ulterior contraponer ese tipo ideal del artesanado, como antítesis, a un tipo ideal correspondiente a una organización industrial capitalista...» (1982: 80).

Un punto importante es que los tipos ideales, en opinión de Weber, no tienen por qué ser exhaustivos respecto a la realidad que conceptualizan. En efecto, al referirse a la tipología ideal más elaborada de las construidas por él - los tipos puros de dominación - el autor aclara dos puntos: i) «... que las asociaciones de dominación pertenecientes a uno u otro de los tipos "puros" hasta aquí considerados son raras en extremo. No hay que olvidar que quedan sin explicar, o sólo se ha hecho en forma vaga, casos importantes dentro de la dominación legal y la tradicional...» y ii) «La terminología y la casuística en modo alguno pueden pretender ser exhaustivas y apresar en sus esquemas la realidad histórica. » (1993b: 211-212). En palabras de Freund: «... ningún sistema es capaz de reproducir íntegramente la infinidad de lo real, ni concepto alguno la diversidad intensiva de un fenómeno particular» (1986: 57).

Vamos a seguir a Freund para plantear una nueva idea de las que estamos intentando sistematizar en este punto: la de que podemos establecer tipos ideales desde distintos puntos de vista sobre un mismo fenómeno social y el número de aquellos que sea necesario. «En caso de necesidad, el sabio puede formar diferentes ideal-tipos de un mismo fenómeno y precisamente el número que le parezca necesario para comprenderlo mejor a partir de todos los puntos de vista posibles. No sólo puede formar un ideal-tipo del cristianismo o... ideal-tipos del cristianismo primitivo, del medieval, del jesuítico, galicano, católico o protestante, sino que, empleando un rasgo característico en lugar de otro (... la organización jurídica de las iglesias o las estructuras sociales), nada le impide elaborar varias construcciones idealtípicas del desarrollo del cristianismo en general o de una de sus formas históricas. » (1986: 62-63). 
Por ultimo, diremos que Weber planteó la utilidad de los tipos ideales para la formulación de hipótesis o, más bien, para «señalar una orientación a la formación de hipótesis», aunque no nos dejó ningún ejemplo de este aspecto. «Respecto de la investigación, el concepto típico-ideal pretende guiar el juicio de imputación: no es una "hipótesis", pero quiere señalar una orientación a la formación de hipótesis» (1982: 79). En el apartado 4 de nuestro artículo intentaremos desarrollar este punto.

iii) Weber estaba especialmente preocupado con el uso de tipologías ideales como la de los modos de producción de Marx, los cuales están «elaborados en la forma de una clasificación genética». Nuestro autor pensaba, y el tiempo le dio la razón, que: «En interés de la demostración intuitiva del tipo ideal o del desarrollo típico-ideal se procurará ilustrarlo mediante material de intuición extraído de la realidad empírico-histórica. El peligro de este procedimiento en sí totalmente legítimo reside en que el saber histórico aparece aquí como servidor de la teoría y no a la inversa. Hay la tentación, para el teórico, de considerar esta relación como normal o, lo que es peor, de trocar los papeles de teoría e historia, confundiéndolas de este modo». Cuando definimos una tipología ideal genética, asumimos dos riesgos, según Weber. El primero es que: «La serie de los tipos, que resulta de las características conceptuales escogidas, aparece entonces como una secuencia histórica legalmente necesaria». El segundo es que: «El ordenamiento lógico de los conceptos, por un lado, y la disposición empírica de lo conceptuado en el espacio, el tiempo y el encadenamiento causal, por el otro, parecen ligados tan estrechamente que la tentación de violentar la realidad para justificar la validez real de la construcción se vuelve casi irresistible» (1982: 9192).

Autores como Nicholas Abercrombie han establecido que: «Marx mismo, a lo largo de El Capital, incluye análisis de la sociedad inglesa. Pero estos análisis no han de verse como verificaciones de su teoría, sino como ilustraciones de la misma» (Abercrombie, 1982: 154). El problema es que los marxistas ortodoxos no entendieron este punto o no lo quisieron entender cayendo en todos los errores posibles en la interpretación de una tipología ideal genéticamente elaborada advertidos por Weber.

iv) Para Weber, la presencia de tipos ideales en una disciplina como la sociología es deseable en todos sus estados. Los tipos ideales no son un síntoma de la juventud científica de aquella, tal como sus colegas contemporáneos de la disciplina histórica señalaban. La presencia de éstos - según Weber- es el resultado lógico de una ciencia que está condicionada por la circunstancia de que «el flujo en eterno progreso de la cultura plantea problemas siempre nuevos». Esto implica que los tipos ideales deben ser re-elaborados y remplazados por otros nuevos desde el momento en que la realidad social se encuentra en continua evolución. En relación con las disciplinas históricas, que, según nuestro autor, se caracterizan por una eterna juventud, afirma: «Pertenece a la esencia de su tarea superar todas las construcciones típico-ideales, pero también construir, inevitablemente, otras nuevas» (1982: 93 y 94$)$. 


\section{PERO, ¿CÓMO SE CONSTRUYE UNA TIPOLOGÍA IDEAL?}

Debemos comenzar señalando que existen diferentes clases de tipologías ideales, asumiendo con Albrow que «no existe un inventario exhaustivo de las variedades y usos de los tipos ideales». No lo puede haber, según este autor, porque «representan la suma total de las imágenes mentales de la realidad posible» (Albrow, 1991: 86). Si atendemos al criterio simple del número de tipos que componen una tipología y nos basamos en las que conocemos, podemos distinguir dos clases: múltiples y simples. Así, las múltiples serían aquellas compuestas por dos o más tipos, mientras que las simples serían las que incluyen un solo tipo ideal para el mismo concepto. Un ejemplo de tipología múltiple es el de los diferentes modos de producción definidos por Marx. Un caso de tipología simple es la conocida burocracia de Weber: un tipo ideal de organización social único en la definición de este concepto. Además del anterior, podemos utilizar otros criterios de clasificación como el de la naturaleza de la relación entre los tipos si es que éstos son varios. Podemos hablar entonces de tipologías ideales independientes y dialécticas. La primera clase es aquella donde los tipos ideales no tienen ninguna relación entre sí, salvo la de haber sido formulados para un mismo concepto. Las dialécticas son aquellas tipologías en las que los dos tipos definidos han sido formulados a partir de una lógica dialéctica. Un ejemplo sería la comunidad y la asociación (Gemeinschaft und Gesellschaft) definidas por Tönnies, similares aunque más específicas y sin el carácter dinámico de la comunización y la socialización (Vergemeinschaftung und Vergesellschaftung) definidas por Weber (1993b: 33). Albrow, por su parte, habla de tipos ideales de primer y de segundo orden cuya esencia nos aclara con el ejemplo de los tipos ideales alrededor de los cuales gira la sociología del derecho de Weber (de segundo orden) y los tipos ideales que determinan la orientación a la acción de los abogados (de primer orden) (1991: 87).

En cuanto al procedimiento de elaboración de tipologías ideales vamos a definir cuatro posibilidades, que desarrollaremos con detalle más adelante. La primera y más simple es la de elegir una parcela de la realidad social y construir un tipo ideal de ella. Un ejemplo, sería el trabajo enajenado de Marx tal como aparece en los "Manuscritos" (1989: 103-119). La segunda es aquella en la que a partir de una revisión amplia de casos empíricos respecto a un concepto (por ejemplo, la economía agraria) formulamos una tipología ideal. El resultado puede ser una tipología múltiple de economías agrarias como la obtenida por Weber en su "Historia Económica General" (1923) o una tipología doble de carácter dialéctico como la de las economías agrarias campesina y capitalista. Esta tipología aparece en los trabajos de Chayanov. Concretamente en su "Teoría económica campesina" (1974). Ello, aunque este autor no se basó en una revisión histórica para elaborar su lógica económica campesina y distinguirla de la capitalista, sino en el análisis de los balances económicos de las explotaciones campesinas rusas de principios del siglo veinte. El procedimiento que nos ocupa es el más laborioso, ya que, si no se tiene un vasto conocimiento histórico 
como el que poseía Max Weber, hay que dedicar una gran cantidad de tiempo al estudio de las formas reales que ha tomado el concepto en cuestión en diferentes partes del mundo y durante distintos períodos de la historia.

La tercera forma de elaborar tipologías ideales es la de razonar un concepto de forma dialéctica. Quizás sea el procedimiento más común. Existen numerosos ejemplos del resultado de aplicar una lógica dialéctica para formular tipos ideales. La mayoría de ellos giran en torno a las ideas de lo tradicional y lo moderno $\mathrm{o}$, dicho de otro modo, la asunción de que un concepto se puede tipificar idealmente para dos momentos históricos como el pasado y el presente o el presente y el futuro. Véanse las dicotomías clave en la obra de los clásicos de la sociología (Giner, 2001: 274). Si se nos pidiera un ejemplo basado en la oposición del presente y el pasado respecto a un concepto confrontaríamos la sociedad corporativa de Giner y Pérez Yruela (1979) con la sociedad de clases según el esquema marxista. Pero, también podemos encontrar otras tipologías dialécticas que no atienden al tiempo como la que elaboraron Sorokin y Zimmermann (1929) para establecer las diferencias sociales entre el campo y la ciudad, o sea, sus conceptos de lo rural y lo urbano tal como se definen en los "Principios de sociología rural-urbana". La cuarta manera de construir un tipo ideal que vamos a considerar es la de proyectar hacia el futuro un concepto a partir de una tendencia social. La burocracia weberiana es un ejemplo del resultado de seguir este procedimiento. La tendencia en este caso es la racionalización de la sociedad. Esta forma de hacer nos lleva a una tipología simple.

Existen dos fases comunes a todas las formas de proceder explicitadas en el párrafo anterior. Nos referimos a la penúltima y última de las operaciones que debemos llevar a cabo. Vamos a comenzar por ellas para luego entrar en las fases previas distintivas de cada uno de los cuatro procedimientos a los que nos estamos refiriendo. La que hemos denominado penúltima fase en la construcción de tipos ideales es aquella en la que debemos seleccionar las variables o macrovariables (para nosotros, indicadores típicos) que van a dar forma a nuestros tipos ideales. De acuerdo con Combessie (2000: 99), "A una variable se le da el nombre de indicador si se considera que constituye un resumen satisfactorio de una noción más abstracta y más amplia; el indicador propone una medida de dicha noción a través del modo en que se distribuyen sus valores o caracteres... Se pueden asociar varios indicadores a un mismo concepto... Uno de los objetivos de la investigación es precisamente reunir indicadores variados y pertinentes con relación al tema que se desea estudiar. ». El criterio para la selección de los indicadores típicos estará condicionado por el objetivo de nuestra investigación y no agota otras posibilidades futuras. Puede que de momento sólo nos interesen aspectos económicos de un concepto, o que precisemos centrarnos en factores sociales, políticos, ideológicos, espirituales, etc. Por ejemplo, Max Weber, en su elaboración del tipo ideal capitalismo realizada en la "Ética Protestante" sólo está interesado, en ese momento como dejó claro (1993a: 261-262), en aspectos espirituales, mientras que Marx, al definir su tipo ideal de sociedad denominado igualmente capitalismo se basó en factores económicos. Por supuesto los resul- 
tados fueron muy distintos, pero ambos tipos resultaron y resultan útiles. El primero para explicar los orígenes de la sociedad resultante de la revolución industrial en sus aspectos económicos y sociales. El segundo, para analizar la dinámica interna de ese mismo tipo de sociedad.

La última fase en la elaboración de tipos ideales consiste en dar lo que vamos a denominar valores típicos a los indicadores seleccionados. Recordemos que se trata de acentuar unilateralmente determinadas características de un concepto. Esta fase final es aquella en la que tenemos que recurrir al método de intuición comprehensiva propuesto por Weber, según el cuál debemos elegir valores típicos con el criterio de que éstos estén relacionados entre sí para que el tipo ideal resultante tenga coherencia interna respecto a dichos valores o, dicho de otro modo, para que la relación entre los valores típicos definidos sea lógica. Dicho de un modo simple, la intuición comprehensiva consiste en tener en mente las diferentes características del concepto a tipificar (indicadores típicos y sus posibles valores) y mediante un esfuerzo de análisis y sintesis e interrelación múltiple construir un todo abstracto pero coherente.

Veamos ahora cuales son las fases previas en la formulación de tipos ideales para cada procedimiento de los que estamos considerando. Respecto al primero, hay poco que decir. Si acaso que nuestra orientación de valor, tal como explicitó Weber, pesará a la hora de elegir el concepto a tipificar. Probablemente, el joven Marx, mucho más filosófico que el maduro y el tardío, estaba muy preocupado con la anomia y alienación que observó producían los trabajos en las factorías de mediados del siglo diecinueve y es por ello por lo que dio más importancia al trabajo y sus aspectos filosóficos que a la propiedad y sus implicaciones económicas al definir el concepto de trabajo enajenado. En relación con el segundo procedimiento, ya hemos adelantado que comenzaremos con una revisión de las formas que adopta la parte de la realidad social que queremos tipificar en distintas regiones o países y en diferentes momentos históricos. Esta primera fase tendrá un carácter descriptivo.

Un excelente ejemplo de tipología ideal a partir de una revisión histórica, aunque su autor no la explicite como tal, son los tipos de reforma agraria formulados por Manuel Pérez Yruela (1997: 884-886). A partir de una revisión exhaustiva de las reformas agrarias llevadas a cabo en distintas partes del mundo y momentos históricos, Pérez Yruela selecciona tres indicadores típicos (sistema político, estructura agraria y estructura social) a partir de los cuales define cuatro tipos ideales de reforma agraria: revolucionaria, liberal-democrática o tradicional, técnica e integral.

En cuanto a la naturaleza de las fases iniciales del tercer procedimiento, el dialéctico, ésta dependerá de que nuestro referente de base para la construcción de tipos ideales sea concreto o abstracto. Si este fuera concreto deberemos partir de realidades al igual que en el segundo procedimiento. Una ilustración de este caso es la tipología dialéctica de economías presentada por Max Weber como «noción previa» al inicio de su "Historia económica general". Nos referimos a las «en sus puras formas conceptualmente antagonicas» economías con- 
suntiva y lucrativa, definidas, respectivamente, como aquella que «implica una acción económica orientada a cubrir las propias necesidades» y la que «implica una orientación en el sentido de las probabilidades de ganancia» (1987: 7-9). Si partimos de un referente abstracto habrá que elegir las oposiciones relevantes para nuestros objetivos de investigación presentes en el concepto a tipificar ideal y dialécticamente. La mayoría de los tipos ideales dialécticos surgen de una visión pesimista de la evolución de la sociedad como la que ostentaron los clásicos de la sociología. Véanse las dicotomías Gemeinschaft und Gesellschaft de Tönnies, solidaridad mecánica y solidaridad orgánica de Durkheim, etc. Aunque también nos encontramos tipos ideales dialécticos procedentes de una visión más optimista, o interventora, como la de Parsons sobre la evolución social. Las variables pauta de Parsons pueden ser entendidas como los valores típicos de cinco indicadores utilizados para definir una tipología ideal dialéctica compuesta por lo tradicional y lo moderno. Los referentes de base en todos los últimos casos mencionados son al mismo tiempo concretos y abstractos. Podríamos pensar que fueron más abstractos en el caso de los clásicos de la sociología porque ellos intuían el futuro como referente de uno de los elementos de sus tipificaciones ideales dialécticas. Pero, podemos decir que Parsons no partió de una recopilación de realidades, sino que intentó montar una tipología que encajara con el armazón, o quizás "corset", de su teoría, obviando otras realidades que no fueran la suya, en relación con la cuál concebía la otra, la del pasado, la del atraso. Adoptando así un modo de hacer absolutamente etnocéntrico y ahistórico, si acaso fuerte y explícitamente inspirado en las tipologías ideales dialécticas de los clásicos, tal como han señalado varios autores.

Respecto al cuarto procedimiento, el que se basa en la observación de una tendencia en la sociedad, podemos decir que es el más abstracto en su referente de base. Además de ello, es importante señalar que la racionalización de la sociedad percibida por Max Weber no sólo le invita a tipificar idealmente las organizaciones sociales del futuro respecto a su tiempo, sino que conforma la construcción del tipo ideal burocracia. Todas las características o valores típicos de la burocracia son definidas de acuerdo con la tendencia observada. El Cuadro 1 es un intento de síntesis de lo expuesto en este apartado de nuestro artículo.

Lo que sigue es una "hipótesis" sobre el uso de tipos ideales por parte de Alfonso Ortí. Llevo años intentando darle sentido a los esquemas conceptuales de evolución de la sociedad o "cromos", como él los llama, de Ortí. En mi opinión, lo que hace este autor no tiene parangón, a pesar de que él no desee seguir a Weber, como yo, y sea muy crítico respecto a este autor. También hay que tener en cuenta que enseñar sociología a economistas, como ha hecho Ortí, o a ingenieros, como es mi caso, te obliga a sistematizar y esquematizar ideas que se expresan mejor en un texto seguido, pero que tienen más sentido en forma de esquemas o expresiones "pseudomatemáticas" más inteligibles para personas con una formación dentro de lo que suele llamarse las "ciencias duras". La mayoría de los esquemas de Ortí combinan tipos ideales dialécticos cruzados en ejes coordenados para llegar a lo que él llama la "curva de la modernización o "M"': 
Cuadro 1

Procedimientos para elaborar tipologías ideales

\begin{tabular}{|c|c|c|c|}
\hline $\begin{array}{c}\text { ABSTRACCIÓN } \\
\text { SIMPLE }\end{array}$ & $\begin{array}{c}\text { REVISIÓN } \\
\text { HISTÓRICA }\end{array}$ & $\begin{array}{c}\text { LóGICA } \\
\text { DIALÉCTICA }\end{array}$ & $\begin{array}{c}\text { TENDENCIA } \\
\text { SOCIAL }\end{array}$ \\
\hline Selección del concepto a tipificar idealmente guiada por nuestra orientación de valor \\
y/o las necesidades de nuestra investigación
\end{tabular}

Fuente: elaboración propia

Una diagonal que pasa desde el punto cero del cruce de abscisas y ordenadas donde sitúa los tipos ideales dialécticos, "tradicionales" y "modernos", hasta la parte más alta del esquema con él que representa sus ideas. Dentro del cuadro conceptual donde sitúa los tipos ideales, que toma de los clásicos, elabora otros de su propio cuño. Es una forma de explicar conceptos sociológicos complejos a personas sin una formación en nuestra disciplina. Mi colega y amigo Alfonso Ortí está convencido de que la sociedad sigue una tendencia social que la lleva a la Modernización o lo que él llama de forma despectiva y en broma "curva de la mier..." (coincido con él totalmente en este punto), teniendo en cuenta que esta evolución nos lleva a algo peor de donde nos encontrábamos, a la insolidaridad, a la falta de ayuda mutua, al individualismo, al materialismo, etc. Esa es la pauta que sigue en todos sus esquemas. Ortí, al que muchos de sus discípulos le debemos mucho, ha aportado gran cantidad de ideas a la sociología desde su formación filosófica, economista, sociológica y humana. Me refiero no sólo a sus 
trabajos de campo y a sus contactos con colegas, sino a su disposición a ayudar a todos los aprendices de la disciplina como yo me considero. Al autor al que me estoy refiriendo, aparte de lo que ha aportado a la metodología de los Grupos de Discusión y su aplicación a estudios concretos, así como otros muchos trabajos (especialmente en torno a Joaquín Costa), le debemos todos mucha cantidad de aportación teórica sociológica. No obstante, desde aquí quiero discrepar con él sobre Weber y su metodología sociológica. Ambos somos "marxistoides", que no marxistas o marxianos, como dirían otros. Hemos sabido, él mejor que yo, por supuesto, interpretar a Marx. Pero yo, a pesar de mi "marxianismo temprano", me siento weberiano, quizás por mi formación ingenieril, que él no alcanzó a pesar de los deseos de su familia. Mi padre sí me obligó a hacerme ingeniero aunque tardé poco en pasarme a las ciencias sociales gracias a Eduardo Sevilla. Desde aquí un homenaje a mis maestros y amigos Alfonso Ortí y Eduardo Sevilla: unos de los mejores sociólogos de mi país. Debo darle las gracias por sus comentarios a este artículo. Es un honor para mí que me haya dicho Alfonso que aprendió algo de mí con la lectura de este escrito. Yo lo sigo con gran admiración y lo seguiré siempre.

\section{Y... ¿PARA QUÉ SIRVEN REALMENTE LOS TIPOS IDEALES?}

Max Weber ya estableció las tres utilidades de una tipología ideal de las que vamos a ocuparnos, pero, como ya hemos señalado, apenas desarrolló sus indicaciones, ni dio ejemplos de ellas. Un tipo ideal o un conjunto de ellos sirven, en primer lugar, para entendernos a la hora de hablar o escribir sobre un concepto. En segundo lugar, una tipología ideal nos permite compararla con la realidad para obtener conclusiones. Por último, los tipos ideales son útiles para la formulación de hipótesis. Veamos con detalle y acudiendo a algunos ejemplos cada una de las aplicaciones que hemos enumerado.

Julián Freund en su análisis de la sociología weberiana señala que: «Puede parecer pedante transformar en ideal-tipos la mayoría de las nociones vulgares empleadas por el historiador y el sociólogo. Sin embargo, sólo con esta condición se llega al rigor conceptual y se evita la retórica vacía, las confusiones lógicas, los equívocos y los errores perniciosos» (Freund, 1986: 60). Es común que los intelectuales que trabajan en un mismo campo de estudio, cuando se reúnen, no se pongan de acuerdo ni siquiera en la definición del terreno en el que van a moverse. Esta es nuestra experiencia en el campo de la Extensión Agraria como parcela de la Sociología Rural. La mayoría de las reuniones científicas comienzan con una discusión interminable sobre qué entendemos por Extensión Agraria. Y es que existen muchas concepciones de ese objeto de estudio. Una forma de solventar esta confusión podría ser establecer una clasificación como aquella que plantea que existen dos formas de extensión agraria: "de arriba abajo" y "de abajo a arriba", según el sentido del flujo de información y considerando que el experto se sitúa metafóricamente arriba mientras que el agricultor permanece 
abajo estableciendo de este modo que existe una relación de subordinación del segundo por el primero. Esa tipología no cubre en absoluto la diversidad de las formas de hacer extensión, probablemente, por utilizar una sola característica, es decir, no evita la «retórica vacía» de la que habla Freund.

La segunda aplicación de los tipos ideales señalada por Weber es la de comparar la realidad con ellos (Giner, 2001: 273 y ss.). En nuestra opinión, no es aconsejable ilustrar los tipos ideales con «material de intuición extraído de la realidad empírico-histórica» como plantéa Weber (1982: 91), ya que ello los desvirtúa frente al lector u oyente. El receptor de esta información ilustrativa pierde de vista las características del tipo ideal que le presentamos para centrarse en el caso real que le es más cercano y fácil de aprehender. Lo que sí podemos hacer es analizar el material empírico en relación con los tipos ideales. Podemos, por ejemplo, ver en qué medida una realidad se acerca a uno o varios tipos ideales, lo cuál nos informará, entre otras cosas, sobre el grado de coherencia lógica de aquella, quizás explicándonos las causas de algún error en su funcionamiento.

Tal como Weber reconoció, los modos de producción definidos por Marx eran tipos ideales y esta convicción no dependía del grado de acuerdo que él pudiera tener con un conjunto de conceptos que ponían la economía en el centro de las relaciones causales. Para Weber, así como para los neo-marxistas de los que vamos a ocuparnos, las relaciones causales son múltiples. El utilizó el espiritualismo como la causa central del capitalismo en la "Ética Protestante", pero lo hizo como aproximación preliminar: «... nuestra intención no es... sustituir una concepción unilateralmente "materialista" de la cultura y de la historia por una concepción contraria de unilateral causalismo espiritualista. Materialismo y espiritualismo son interpretaciones igualmente posibles, pero como trabajo preliminar; si, por el contrario, pretenden constituir el término de la investigación, ambas son igualmente inadecuadas para servir la verdad histórica» (Weber, 1993a: 261-262).

Algunos teóricos marxistas o, mejor, marxianos han intentado ir más allá que el propio Marx en la conceptualización de los modos de producción y su aplicación al análisis de sociedades reales. Nos referimos al trabajo de Althusser y Balibar (1969). Estos autores distinguen entre modo de producción y formación social, entendida como una realidad en la que pueden coexistir varios modos de producción. Esta coexistencia les lleva a hablar de la dominación o de la articulación entre modos de producción dependiendo de que nos encontremos con una situación de subsunción real o formal, respectivamante. Podemos argüir que Althusser y Balibar están tratando con una serie de conceptos que han sido definidos para comparar realidades con ellos y no para analizar su presencia individual o colectiva en dichas realidades. Sin embargo, sus ideas podrían ser útiles para nuestro propósito en este apartado si consideramos que han llegado a un punto que Weber no considero: que en una realidad más compleja que un individuo o una institución podemos encontrar no sólo una combinación de las características de varios tipos ideales, sino, también, partes de dicha realidad cercanas cada una de ellas a un tipo ideal diferente. 
Si tomamos un individuo y comparamos su acción social con las acciones típico-ideales definidas por Weber, llegaremos a la conclusión de que él/ella actúa de una forma cercana a uno de esos tipos. Aunque, también podríamos entrar a analizar las relaciones entre esos elementos de la realidad que estamos observando utilizando las ideas de articulación, dominación, subsunción real o formal. Lo que proponemos no es pensar en la articulación de tipos ideales dentro de una sociedad, como hacen Althusser y Balibar, sino en la articulación entre elementos de una realidad social utilizando los conceptos ofrecidos por una tipología ideal de ésta.

La tercera utilidad de los tipos ideales es la de formular hipótesis a partir de ellos. Kalberg ha señalado que: «... éstos ofrecen hipótesis delimitadas que pueden ser contrastadas con casos empíricos específicos... con relaciones... y con desarrollos, aislando de este modo regularidades causales discretas y significativas» (Kalberg, 1994: 93-95), aunque no llega a ilustrar su afirmación.

Un ejemplo de hipotesis formulada a partir de la relación entre dos tipos ideales puede ser encontrado en la "Historia económica general". En relación con los tipos ideales de economía consuntiva y lucrativa, Weber establece que éstas «no se distinguían en los siglos XIV y XV, por ejemplo en la casa de los Médici», pero en la actualidad (1920) «se encuentran separadas y se perfeccionan o realizan mediante actividades diferenciadas y continuas... hasta el punto que no sólo se separan externamente la economía consuntiva y el negocio lucrativo - como era, por ejemplo, el caso entre los visires del imperio de los árabes-, sino que resulta también decisiva la separación contable.» (1987: 8-9).

\section{A MODO DE CONCLUSIÓN}

Existen numerosas clases de tipos y tipologías en sociología. Desde los conglomerados o "clusters" estadísticos cuantitativamente definidos a partir de un referente de base concreto, hasta los cualitativos tipos folk hermeneúticamente construidos, pasando por los tipologías concretas al modo de Lazarsfeld. Sin embargo, como ha señalado López R., en un trabajo en el que clasifica aquellas, «poco se ha hecho para contribuir metodologicamente sobre su naturaleza o sobre los procesos de construcción» (Lopez R., 1996: 10). Con este artículo hemos intentado responder a ese desafío abordando, quizás, la clase de tipificación más olvidada: la propuesta y desarrollada por Max Weber. Como hemos señalado en otro lugar, el propio López R. define el tipo ideal, en el trabajo mencionado, de forma correcta pero superficial, siguiendo un trabajo de Blalock y sin hacer ninguna referencia a su proponente original, a quien sitúa dentro de lo que llama "tipologías analíticas", junto a Tönnies, Comte, Durkheim y Marx, sin ofrecernos ningún ejemplo de autor situado en la categoría clasificatoria "tipo ideal". La razón de esta carencia puede buscarse en un interés central en las tipologías concretas. Debemos señalar que Weber no hizo una labor divulgadora de su concepto, como sí la hizo, por ejemplo, de las ideas de el político y el cien- 
tífico (1991) o de las formas de organización económica, tal como podemos comprobar en su "Historia económica general". Probablemente, dejó el asunto para después de completar su obra teórica, que no llegó a concluir. Sin embargo, en su "Esbozo de sociología comprensiva", que es como se subtitula "Economía y sociedad", lo cual da una idea de lo inacabado de su empresa, así como en los "Ensayos sobre metodología sociológica" y en la "Historia económica general" podemos encontrar las pistas para hacer el trabajo de divulgación y aplicación práctica que nos hemos propuesto. Esperamos no haber interpretado erróneamente ninguna de las ideas originales de Max Weber. Incluso, tenemos la esperanza de haber desarrollado alguna idea extra que él no detectó o explicitó. 


\section{BIBLIOGRAFÍA}

ABERCROMBIE, N. (1982), Clase, estructura y conocimiento, Barcelona, Ediciones Península.

AlBrow, M. (1990), Max Weber's Construction of Social Theory, London, Macmillan. AlBrow, M. (1991), "Las sociedades como hechos construidos: El enfoque weberiano de la realidad social”, en González de la Fe, M.T. (ed), Sociología: Unidad y Diversidad, Madrid, Consejo Superior de Investigaciones Científicas, pp. 75-92.

Althusser, L. y Balibar, E. (1969), Para leer el Capital, México, Siglo XXI.

Burguer, T. (1987), Max Weber's Theory of Concept Formation, Durham, Duke University Press.

COMBESSIE, J.C. (2000), El método en sociología, Madrid, Alianza Editorial.

Chayanov, A.V. (1974), La organización de la unidad económica campesina, Buenos Aires, Nueva Visión.

FREUnd, J. (1975), Las teorías de las ciencias humanas, Barcelona, Ediciones Península.

Freund, J. (1986), Sociología de Max Weber, Barcelona, Ediciones Península.

Giner, S. (1978), Historia del Pensamiento Social, Barcelona, Editorial Ariel.

Giner, S. y Perez Yruela, M. (1979), La Sociedad Corporativa, Madrid, C.I.S.

GINER, S. (2001), Teoría sociológica clásica, Barcelona, Ariel.

Hekman, S.J. (1983), "Weber's Ideal Type: A Contemporary Reassessment", Polity, vol. 16, $\mathrm{n}^{2} 1$, pp. 119-137.

Honigsheim, P. (1977), Max Weber, Buenos Aires, Editorial Paidos.

KALBERG, S. (1994), Max Weber's Comparative-Historical Sociology, Cambridge, Polity Press.

KAPLAN, A. (1964), The Conduct of Inquiry, Scranton, Chandler.

LAZARSFELD, P.L. (1972), Qualitative Analysis, Boston, Allyn \& Bacon.

LINDBEKK, T. (1992), "The Weberian Ideal-type: Development and Continuities", Acta Sociologica, $\mathrm{n}^{2} 35$, pp. 285-297.

LOPEZ R., P. (1996), "La construcción de tipologías: metodología de análisis", Papers, n⿳ 48, pp. 9-29.

MARX, K. (1989), Manuscritos: economía y filosofia, Madrid, Alianza Editorial.

NorgaARd, R. B. (1994), Development Betrayed. The End of Progress and a Coevolutionary Revisioning of the Future, London, Routledge.

Pérez Yruela, M. (1997), "La reforma agraria en España", en Gómez Benito, C. y González, J.J. (coords.) (1997), Agricultura y sociedad en la España contemporánea. Madrid. CIS-MAPA, pp. 883-911.

SÁNCHEZ DE PUERTA, F. (1994), «Comprehensive sociology and agricultural extension. Rethinking ideal types with cognitive and normative ends», en THØGERSEN, J.O et al. (eds), Proceedings of the $11^{\text {th }}$ European Seminar on Extension Education 1993, Aarhus (Dinamarca), pp. 31-41,

SÁNCHEZ dE PUERTA, F. (2002), "Sociology, typology and extension: new issues", Agricoltura Mediterránea. International Quarterly Journal of Agricultural Science, vol. 2, pp. 34-49.

STINCHCOMBE, A. (1968), Constructing Social Theories, New York, Harcourt Brace.

SOROKIN, P. y ZiMmERMAN, C.A. (1929), Principles of rural-urban sociology, New York, Henry Holt. 
WEBER, M. (1991), El político y el científico, Madrid, Alianza Editorial. (Politik als Beruf, Wissenschaft als Beruf, 1919)

WEBER, M. (1993a), La ética protestante y el espíritu del capitalismo, Barcelona, Ediciones Península. (Protestantische Ethik, 1904-5)

WebER, M. (1993b), Economía y sociedad. Esbozo de sociología comprensiva, México, D.F., Fondo de Cultura Económica. (Wirtschaft und Gesellschaft. Grundiss der Verstehender Soziologie, 1922)

WEBER, M. (1982), Ensayos sobre metodología sociológica, Buenos Aires, Amorrortu Editores. (Gesammelte Aufsätzê zur Wissenschaftslehre, 1922)

WeBer, M. (1987), Historia económica general, México, D.F., Fondo de Cultura Económica. (Wirtschaftsgeschichte, 1923) 


\section{RESUMEN}

El concepto de tipo ideal de Max Weber ha sido utilizado de forma implícita y explícita por numerosos autores antes y después de que su proponente lo enunciara y desarrollara a principios del siglo veinte. Sin embargo, poco ha sido escrito sobre la manera de elaborar una tipología ideal, ni sobre el modo en que ésta puede ser utilizada. En este artículo se abordan esas cuestiones. Después de recurrir a Weber para conocer la esencia del concepto y sus implicaciones, tal como aparecen en su obra, se ofrecen dos apartados en los que se presentan cuatro procedimientos posibles para la construcción de tipos ideales, denominados de forma resumida: abstracción simple, revisión histórica, lógica dialéctica y tendencia social, así como tres clases de aplicaciones prácticas: la del entendimiento común a la hora de abordar un concepto, la de la comparación de una realidad con uno o varios tipos ideales para la obtención de conclusiones y la de formular hipótesis. De esta última se consideran tres opciones: formular hipótesis sobre un tipo y las relaciones internas de sus características, hacerlo sobre la relación entre dos tipos ideales y elaborar hipótesis sobre la evolución de un tipo ideal a partir de una tendencia social.

\section{PALABRAS CLAVE}

Tipo ideal, Metodología, Hipótesis

\section{ABSTRACT}

Max Weber's concept of ideal type has been used both in implicit and explicit ways by numerous authors, before and after it was proposed and developed by him from the beginning of the $20^{\text {th }}$ century. However, there is not much written neither about how an ideal typology can be built nor the way it can be used. In this article these questions are approached. After referring to Weber in order to know the essence of the concept and its implications as they appear in his work, there are two sections in which four possible procedures to elaborate ideal types are presented, which can be called, in short, simple abstraction, historical revision, logical dialectics and social trend, as well as three different kinds of practical applications: that of common understanding when approaching to a concept, that of comparing a reality to one or several ideal types for obtaining conclusions and that of formulating hypothesis. We consider three options from the last one: formulating hypothesis about one type and its features internal relations, about the relationship between two ideal types and, finally, about the evolution of an ideal type from a social trend. 
32 FERNANDO SÁNCHEZ DE PUERTA TRUJILLO

\section{KEY WORDS}

Ideal Type, Methodology, Hypothesis. 